\title{
O CONCEITO DE CULTURA SEGUNDO FUTUROS BIBLIOTECÁRIOS
}

\author{
THE CONCEPT OF CULTURE BY FUTURE LIBRARIANS \\ EL CONCEPTO DE CULTURA POR LOS FUTUROS BIBLIOTECARIOS
}

\author{
Hellen dos Santos Nunes \\ Universidade Federal do Espírito Santos (UFES) \\ E-mail: hellenuness@gmail.com \\ Agência: CAPES
}

RESUMO

\begin{abstract}
O artigo pretende observar como alunos do curso de biblioteconomia conceituam Cultura, a partir da análise de textos desenvolvidos por estudantes do primeiro período em que foi solicitado que se estabelecesse a relação entre cultura, educação e leitura. Por se tratar de profissionais que futuramente lidarão com um grande público, sendo responsáveis por organizar e promover a leitura (em ambiente escolar ou não), suas concepções podem afetar a forma que desenvolverão seu trabalho, privilegiando determinados aspectos em detrimento de outros, o que pode influenciar as decisões e percepções dos usuários desses espaços. Os textos recolhidos foram analisados comparativamente a partir do referencial teórico escolhido. O resultado mostra que os diferentes conceitos de cultura que os estudantes carregam consigo influenciam a forma como cada um definiu o termo, o que também pode influenciar suas futuras ações como profissionais.
\end{abstract}

PALAVRAS-CHAVE: Cultura. Estudantes. Biblioteconomia.

\section{ABSTRACT}

The article intends to observe how students of the Library Science course conceptualize Culture, analyzing texts developed by students of the first semestre which it was asked to connect culture, education and reading. As professionals who will deal with a large audience in the future, responsible for organizing and promoting reading (in school or anothers environment), their conceptions may affect the way they will develop their work, favoring some aspects, which can influence the decisions and perceptions of users of these spaces. The texts collected were analyzed comparatively from the theoretical framework chosen. The result shows that the different culture concepts that students have influence the way each one defines the term, which can also influence their future actions as professionals.

KEYWORDS: Culture. Students. Library Science.

\section{RESUMEN}

El artículo pretende observar cómo los estudiantes del curso de bibliotecología conceptualizan la cultura, a partir del análisis de textos desarrollados por los estudiantes del primer período en el que se solicitó establecer la relación entre cultura, educación y lectura. Como son profesionales que tratarán con un gran público en el futuro, responsables de organizar y promover la lectura (en la escuela o em otros entornos), sus concepciones pueden afectar la forma en que desarrollarán su trabajo, favoreciendo ciertos aspectos, influenciando en las decisiones y percepciones de los usuarios de estos espacios. Los textos recogidos fueron analizados comparativamente a partir del marco teórico elegido. El resultado muestra que los diferentes conceptos culturales que los estudiantes tienem influyen en la forma que cada uno define el término, lo que también puede influir en sus acciones futuras como profesionales.

PALABRAS-CLAVE: Cultura. Estudiantes. Bibliotecología. 


\section{INTRODUÇÃO}

Ao longo da história da humanidade, diversas foram as formas empregadas para transmitir conhecimento: de desenhos nas cavernas até os meios cibernéticos mais modernos, passando pela tradição oral e os manuscritos, o homem tenta aprender com o passado e transferir seu legado ao futuro. Entre todos os instrumentos existentes, a escrita se fixou hegemonicamente devido à sua capacidade de armazenar e de disseminar informação de maneira prática.

Um dos grandes veículos utilizados nessa empreitada, apesar dos avanços tecnológicos, ainda é o livro. Em formato digital ou impresso, obras de distintas naturezas (literárias, acadêmicas, enciclopédicas etc.) são utilizadas como forma de compreender ciências, sentimentos e pessoas, criando e modificando conceitos sobre o mundo ao redor. $\mathrm{O}$ acesso a esse conhecimento muitas vezes é possibilitado através de bibliotecas, que permanecem mesmo no mundo moderno como uma porta de acesso à informação, apresentando relativa vantagem em relação à internet, grande fonte de consulta atual: os dados obtidos nas bibliotecas apresentam uma espécie de chancela, um selo de qualidade e confiabilidade, garantia difícil de ser mantida durante a navegação na web devido às inúmeras fontes que se confundem na rede.

O bibliotecário é a figura que encarna a credibilidade presente nesses ambientes, sendo, sobretudo nas bibliotecas escolares, uma das principais fontes a que se recorre durante pesquisas ou sugestão para leitura. Tal fato mostra a importância de saber a concepção que esses profissionais têm sobre cultura, já que suas indicações literárias podem ser capazes de influenciar leitores e suas percepções. Como aponta Silveira (2010, p. 69), essa é a função social das bibliotecas, principalmente as públicas:

[...] preservar, organizar e disseminar os elementos culturais e os insumos de conhecimentos concebidos por nosso fazer racional. Ou seja, enquanto "lugares de memória", as bibliotecas tendem a reafirmar os saberes e a tornálos móveis, traduzíveis, permutáveis, enfim, tentam dar sentido ao saber e fazer com que o mesmo se torne um instrumento de reafirmação da "identidade" individual ou coletiva humana.

Nesse sentido, o aprendizado sobre as culturas ocupa espaço significativo ao auxiliar na capacidade de percepção do eu e do outro, podendo ambos formarem conjuntamente um coletivo quando se reconhece nele um ser tão complexo e dinâmico como si próprio. Ou, dependendo da forma como o conhecimento é repassado/absorvido, pode-se ter o efeito contrário: a visão do outro como algo estranho e por isso passível de ser evitado e até mesmo 
excluído. Pessoas (e por conseguinte suas culturas) podem, portanto, ser percebidas como semelhantes e, por isso, próximas, ou como diferentes e, consequentemente, distantes. Tais concepções ocorrem ao longo da formação do indivíduo, que não se limita a ambientes tradicionais como família e escola, mas se expande para demais espaços que ele ocupa em sua vida. A biblioteca é um deles.

Considerando tal contexto, este artigo busca analisar como os futuros profissionais, estudantes do primeiro período de Biblioteconomia, definem "cultura" a partir de textos desenvolvidos em aula de Língua Portuguesa no curso da Universidade Federal do Espírito Santo. Para isso, primeiramente são traçadas algumas considerações sobre esse conceito a partir da visão de diferentes teóricos das Ciências Humanas.

\section{REFERENCIAL TEÓRICO}

É consenso entre os estudiosos de qualquer teoria ou área que resolva se debruçar sobre a cultura que se trata de um tema de difícil definição, no entanto (ou exatamente por esse motivo) os estudos do assunto se multiplicam no campo das Ciências Humanas. Segundo Santos (2006, p. 7), isso ocorre devido à "preocupação em entender os muitos caminhos que conduziram os grupos humanos às suas relações presentes e suas perspectivas de futuro". As variadas formas de culturas existentes ao redor do mundo sempre tiveram contato em maior ou menor grau, com resultados diversos, da convivência pacífica a conflitos que provocaram grandes guerras ao longo da história da humanidade. Todas as reações foram geradas pelo choque em conviver com o diferente pois "são complexas as realidades dos agrupamentos humanos e as características que os unem e diferenciam" (SANTOS, 2006, p. 7).

$\mathrm{O}$ autor destaca ainda que "é sempre fundamental entender os sentidos que uma realidade cultural faz para aqueles que a vivem" (2006, p. 8), pois todas têm sua lógica interna, criada a partir de suas vivências, costumes e tradições, fazendo sentido para os integrantes daquela comunidade. Assim as ações de um determinado grupo podem parecer estranhas a outro, porém sua história apresenta em algum momento uma explicação para tal ato. É claro que muitas vezes a motivação inicial para esse ou aquele aspecto cultural não é de conhecimento de todos, mas ainda assim é aceito por um processo que pode ser chamado de sedimentação da cultura, como aborda Kramsch (2011, p. 7, tradução nossa ${ }^{1}$ ) ao afirmar que:

as formas culturais que podem ser identificadas a qualquer momento evoluíram e se solidificaram ao longo do tempo, razão pela qual elas são tão 
frequentemente tomadas por um comportamento natural. Elas se sedimentaram nas memórias de membros do grupo que as experimentaram em primeira mão ou simplesmente ouviram falar sobre, e que as transmitiram no discurso e na escrita de uma geração para outra. [...] A cultura das práticas cotidianas se desenha na cultura da história e das tradições compartilhadas.

Esse processo, porém, não implica necessariamente na sua solidificação da cultura, ou seja, o fato de as práticas culturais serem formadas a partir da sedimentação de ações não significa que elas não possam sofrer alterações no decorrer do tempo. A autora destaca que as culturas são heterogêneas e mudam constantemente (KRAMSCH, 2009, p. 10). Tal visão é corroborada por Santos (2006, p. 47) que afirma que a possibilidade de identificar uma tradição como comum não significa que ela não seja capaz de se transformar. Segundo o autor, "nada do que é cultural pode ser estanque, porque a cultura faz parte de uma realidade onde a mudança é um aspecto fundamental".

Por ser capaz de se alterar ao longo do tempo, modifica-se também a forma como ela é enxergada por cada povo. Isso porque segundo Santos (2006, p. 16),

a avaliação de cada cultura e do conjunto das culturas existentes varia de acordo com a cultura particular da qual se efetue a observação e análise (...) Verifica-se assim que a observação de culturas alheias se faz segundo pontos de vista definidos pela cultura do observador, que os critérios que se usa para classificar uma cultura são também culturais.

Para ilustrar essa explicação, o autor apresenta como exemplo a Europa ocidental, que ao longo da Era Moderna realizou diversos estudos com o objetivo de hierarquizar as culturas humanas da época ou já extintas, numa tentativa de provar que as civilizações passam por etapas sucessivas de evolução social comuns a todos os povos, saindo da barbárie até alcançar a plenitude que, não surpreendentemente, coincidia com seu estágio àquele período. É claro, portanto, que o objetivo de tais estudos não era a efetiva análise isenta das civilizações, mas uma justificativa para o processo de dominação dos povos colonizados, que, como seres inferiores na evolução social, não mereciam o mesmo status e tratamento aplicado aos europeus.

Tal concepção felizmente vem sendo progressivamente deixada de lado pelos teóricos, como mostra Monte Mór (2002, p. 146) ao retomar os estudos de Sardar \& Van Loon (1997) que percebem que o conceito de cultura se redefine de tempos em tempos. Para comprovar sua tese, os autores listam algumas concepções de cultura: entre a definição de Tylor no início do século XIX, que caracteriza cultura como "um bloco complexo que integra conhecimento, crenças, arte, moral, lei, costumes e outras capacidades e hábitos adquiridos pelo homem enquanto membro de uma sociedade", e o conceito atual trazido por Geetz de "um conjunto de 
histórias que contamos a nós mesmos sobre nós mesmos" percebe-se que o sentido vem se transformando.

Em sua reflexão sobre as posições apresentadas pelos teóricos, Monte Mór aponta que essa alteração tem como ponto de partida uma ideia de cultura única e modelar que servia de exemplo à sociedade, algo comum na Era do Iluminismo, pregador da valorização do que era uno, buscando padrões que convergiam para o controle social. No outro extremo de pensamento se chega à Era da Incerteza, que, segundo a autora, poderia caracterizar as últimas décadas, onde "a pluralidade de crenças, pensamentos, comportamentos e valores tornaram-se socialmente visíveis" (MONTE MÓR, 2002, p. 148), dando espaço à variedade e à incompletude. Incompletude aqui não é tomada como algo imperfeito ou ruim, mas no sentido de algo que não está completo nem acabado, sendo possível modificá-lo constantemente.

Souza (2010) também traz uma retrospectiva dos conceitos de cultura ao longo dos séculos XIX e XX, onde é possível observar conclusões semelhante às apontadas por Monte Mór: saímos da ideia de cultura homogênea que luta contra o caos multicultural, defendido por Arnold, para cultura como "múltiplas ações criadoras efêmeras, às margens das estruturas normatizadoras", como classifica De Certeau. O autor destaca ainda que havia um evidente objetivo entre os primeiros teóricos estudados por ele, como Herder e Locke, de homogeneizar a língua e a cultura da nação: o primeiro buscava o chamado espírito da nação, ou seja, "a sua mais pura verdade", que pudesse ser estendida a todo o país; já o segundo procurou uma padronização da cultura nacional através de "uma voz numa única língua”. Em ambos os casos, percebe-se a presença dos elementos que tentam relacionar a ideia de cultura com a de estadonação.

Hall (2006, p. 49) aborda largamente o assunto, mostrando como as individualidades foram sintetizadas de forma homogênea (mas não pacífica) durante o processo de formação do estado-nação. Ele utiliza o conceito de Gellner para explicar que "as diferenças regionais e étnicas foram gradualmente sendo colocadas, de forma subordinada, sob o chamado 'teto político' do estado-nação, que se tornou, assim, uma fonte poderosa de significados para as identidades culturais modernas". As particularidades, então, são apagadas e em seu lugar surge uma figura única que tem a (ilusória) pretensão de representar a todos.

A fixação dessa figura é consolidada nas "estórias que são contadas sobre a nação, memórias que conectam seu presente com seu passado e imagens que dela são construídas" (HALL, 2006, p. 51). São as chamadas "comunidades imaginadas", conceito criado por 
Anderson que Hall resgata para mostrar que "as diferenças entre as nações residem nas formas diferentes pelas quais elas são imaginadas". As narrativas da nação com suas lendas sobre a criação do Estado e seus heróis, a perpetuação das tradições e a ideia de povo original, puro, são alguns dos pilares que sustentam essa imagem idealizada de nação, que é reforçada pelas estruturas estatais e demais instituições que fazem parte dela.

Ferraz e Silva (2016, p. 226) reforçam ainda que "adotar a cultura como uma nação pode implicar visões peculiarmente generalizantes sobre o Outro". Em outro artigo, Ferraz acrescenta outro adjetivo a essa caracterização: perigoso. Para comprovar sua ideia, ele nos propõe um exercício:

O que vem à nossa mente quando pensamos na cultura francesa? Souvenirs, Paris, a música, o cinema, a romântica língua francesa. São estes aspectos positivos ou negativos? Agora, quando pensamos sobre a cultura iraquiana (ou os árabes, afegãos, paquistaneses), o que vem à nossa mente? Guerra, luta, bombas, morte, homens suicidas, a feia língua árabe. São esses aspectos positivos ou negativos do mundo árabe? Obviamente, nem toda pessoa francesa é romântica ou "culta", assim como nem todo iraquiano é um terrorista. (FERRAZ, 2013, p. 244, tradução nossa²)

Com o objetivo de sustentar a visão idealizada de cultura dentro do estado-nação, realiza-se um processo de estereotipação das individualidades, resultando na classificação de toda uma população como romântica ou terrorista. A idealização do estado-nação, portanto, é problemática pois exclui uma série de realidades locais, apagando histórias e, o que é pior, apagando os grupos que correspondem a essas histórias, fixando apenas uma história como única e verdadeira para uma enormidade de individualidades.

Tomando o Brasil como exemplo, Santos (2006, p. 18) afirma que "existem realidades culturais internas à nossa sociedade que podem ser tratadas, e muitas vezes o são, como se fossem culturas estranhas". Não se trata apenas de grupos indígenas mas também de comunidades que vivem no campo e nas cidades, em lugares isolados ou pequenos coletivos, lutando para proteger sua própria cultura.

Numa tentativa de amenizar esse processo agressivo de apagamento, surgiu a concepção de multiculturalismo, em que as diferentes culturas são agregadas à cultura geral, visão radicalmente combatida por alguns teóricos por ser entendida como tão simplista quanto a de cultura homogênea. Ferraz e Silva (2016, p. 225) afirmam que "a visão multicultural de 'soma das culturas vivendo em harmonia' apenas solidifica o pensamento equivocado de 'cultura' como representante do estado-nação", em que, apesar do discurso de união, ecoa mais alto a negligência ao reconhecimento das diferenças, inerentes a toda e qualquer cultura. 


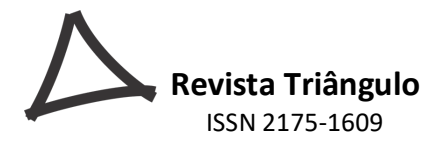

Outra situação igualmente inadequada que ocorre frente à diversidade cultural é a segmentação e consequente hierarquização entre o que é considerado alta cultura e cultura popular. Santos (2006, p. 54) afirma que anteriormente à classificação das civilizações colonizadas como inferiores, no fim da Idade Média, a Europa já diferenciava a cultura tida como popular, e por isso mesmo inferior e atrasada, daquela considerada um "conhecimento erudito ao qual só tinham acesso setores das classes dominantes desses países". Esse conceito ultrapassou fronteiras e tempos e ainda hoje é tomado como verdadeiro em diversas partes do mundo.

Assim como aconteceu na Europa, essa separação entre alta e baixa cultura é realizada pela elite de qualquer país, detentora do que ela própria rotula como alta cultura: está associada à educação formal e a um conjunto específico de artes, onde estão incluídas apenas aquelas a que tem acesso um seleto grupo de pessoas, como a música clássica, o teatro, esculturas, obras e afrescos que envolvem determinadas técnicas adquiridas quase sempre através da instrução formal. Como a educação é negada ou oferecida com uma série de restrições à grande parte da população, as manifestações artísticas dessas camadas não podem ser consideradas alta cultura, merecendo outra classificação, inferior, já que são baseadas em crenças, lenda e cerimônias em geral tidas como supersticiosas.

Para que tal separação não parecesse preconceituosa, optou-se por agregar a esses costumes tidos como inferiores um adjetivo que se considerou isento: típico. Passa-se a ter, então, as comidas típicas, os trajes típicos, as danças típicas, que apesar de serem culturais jamais seriam tomados como eruditos. O que está por trás dessa separação tendenciosa é uma luta de classes que ultrapassa fronteiras e eras:

O que devemos reter dessas discussões é o quanto as concepções de cultura e o próprio conteúdo da cultura estiveram sempre associados às relações entre as classes sociais: a oposição entre cultura erudita e cultura popular é um produto dessas relações. (SANTOS, 2006, p. 58)

Não é, portanto, uma questão de análise específica do conjunto de artes e características que as compõem, mas uma classificação política, social e econômica que, na verdade, diferencia aqueles que as praticam. Se tais conceitos são repassados através das mais diversas formas a toda população, eles serão perpetuados entre seus membros ao longo do tempo, mantendo as classes dominantes e dominadas em seus lugares atuais. 


\section{MATERIAIS E MÉTODOS}

Os estudos discutidos anteriormente mostram como o conceito de cultura não é isento, trazendo consigo uma série de prejulgamento e estigmas carregados ao longo de toda a vida da pessoa e de toda a história da humanidade. Por isso é importante, como apontado no início deste texto, considerar a noção que alguns profissionais têm a respeito da cultura, sobretudo aqueles que apresentam significativa influência sobre determinados ambientes. Aqui analisaremos tal aspecto segundo futuros bibliotecários, hoje estudantes universitários que estão iniciando sua formação profissional.

Para isso foram utilizados textos produzidos por alunos do primeiro período do curso de Biblioteconomia, oferecido pela Universidade Federal do Espírito Santo, produzidos durante as aulas de Língua Portuguesa, em que se solicitou a elaboração de texto, inicialmente composto por um ou dois parágrafos, em que fosse apresentada a definição de cultura, conforme seu entendimento. É necessário destacar que, para evitar influências sobre os alunos, o tema não foi abordado em sala de aula antes do exercício de escrita. Posteriormente, as produções foram discutidas e acrescidas de outras ideias, como a relação entre cultura, educação e leitura, porém, considerando o foco deste artigo, a análise se deterá apenas nos parágrafos iniciais dos textos.

\section{ANÁLISE DOS DADOS E RESULTADOS}

Dentre as definições apresentadas, o conceito mais encontrado está diretamente relacionado à noção de povo, nação ou grupo que poderia ser marcado por determinadas características; entre elas, as mais comuns são aquelas que envolvem a música, a dança e a culinária, o que demonstra uma clara intenção de entrelaçar cultura a tradições. Abaixo seguem alguns exemplos:

\begin{tabular}{|c|c|}
\hline $\begin{array}{c}\text { Texto 1: Cultura é o que define a identidade } \\
\text { de um povo. }\end{array}$ & $\begin{array}{c}\text { Texto 2: A cultura nada mais é do que um conjunto } \\
\text { de práticas que caracterizam determinado grupo ou } \\
\text { região. }\end{array}$ \\
\hline $\begin{array}{c}\text { Texto 3: A cultura é um conjunto de } \\
\text { costumes e outros elementos que fazem } \\
\text { reconhecer povos, como por exemplo leis, }\end{array}$ & $\begin{array}{c}\text { Texto 4: A cultura é um conjunto de costumes e } \\
\text { crenças que predominam num determinado local, }\end{array}$ \\
\hline
\end{tabular}




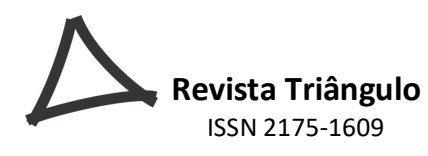

religião, língua, culinária, entre outras características.

sendo através da dança, música, escrita, comida, entre outros.

Os Textos 1 e 2 notadamente associam a cultura à identificação de um povo ou grupo ao usarem respectivamente termos como "define identidade" e "caracterizam determinado grupo", trazendo acepção que, ao definir, também segmenta os povos ou grupos conforme determinadas particularidades. Os Textos 3 e 4 apresentam uma visão um pouco mais ampla sobre cultura, que abarca, além de itens apontados como tradicionais, como culinária, dança e comida, aspectos que influenciam de maneira significativa o cotidiano das sociedades, tornando-se convenções aceitas por todos, como leis, religião e escrita. Cabe ainda destaque à seleção lexical realizada no Texto 4 que opta pelo termo "predominam", o que aponta que não há uma unanimidade nas características descritas, mas sim um domínio maior.

Alguns conceitos apresentados também vincularam a cultura à relação desenvolvida pelos povos internamente ou com outros grupos:

Texto 5: Existem várias formas de se identificar a cultura de um povo, seja ela através da música, arte, religião ou hábitos adquiridos desde a infância através da família.

Texto 6: Cultura são hábitos específicos de cada povo que sobrevivem ao tempo, sendo passado de geração em geração, revelando suas características e a relação daquele povo com o lugar em que vive.

Texto 7: Cultura é tudo aquilo que caracterize os diversos grupos existentes em uma sociedade, envolvendo a língua, as artes, as maneiras de agir, religião, política e tudo mais o que engloba o funcionamento destes grupos e sua interação com outros grupos.

O Texto 5 apresenta as relações familiares desenvolvidas ao longo do tempo como um fator determinante para a cultura, enquanto o Texto 6 acrescenta ainda a força da comunidade e sua atuação sobre o lugar em que vive. Ambos mostram como as relações desenvolvidas com os membros mais próximos são determinantes para que o conceito se fixe na mente do grupo. Além disso, neles está nitidamente marcada a relação entre cultura e tempo, que será discutida mais detalhadamente nos Textos 10 a 13. O Texto 7 inclui também a interação com outros grupos (com outras culturas) como determinante para o conceito.

Os três textos mostram como o conceito é percebido de diferentes formas por cada indivíduo: enquanto para alguns a cultura está circunscrita às práticas aprendidas no ambiente 
familiar, para outros ela se constitui de forma mais ampla, inclusive a partir da convivência com pessoas que não compartilham os mesmos costumes, distinção que deixa evidente a possibilidade de influência que uma cultura pode exercer sobre a outra, já que não se trata de formas estanques ou isoladas. Isso ocorre porque a sociedade apresenta uma heterogeneidade que afasta a ideia de unificação. Essa diversidade também é apontada no Texto 8:

Texto 8: A cultura é um sistema que compreende tudo o que está relacionado com a arte, crenças e tradições que se constroem durante a vida em sociedade. Não existe uma definição precisa do que é ou não cultura, pois o pensar é individual, então cada ser tem uma compreensão de cultura.

Texto 9: Cultura é o ideal espelhado de uma sociedade, é o que forma uma nação, que nos mostra seus pensamentos, raízes e tradições. A cultura é rica e mutável. É o que nos diferencia do restante do planeta, pois cada povo possui suas peculiaridades, mas é sinal de união também entre os seus em sua propagação e os demais ao compartilhar entre suas culturas a aprendizagem que as enriquecem e a nutrem ainda mais.

Apesar de a primeira frase do Texto 8 apresentar algumas ideias generalizantes de arte, crença e tradições, a segunda procura dissociar a cultura da homogeneidade ao afirmar a imprecisão do termo já que "o pensar é individual” e, portanto, "cada ser tem uma compreensão de cultura", o que aponta para o entendimento de que tal conceito será visto de diferentes formas, conforme concepções individuais. Situação bem diferente é expressa no Texto 9, que apresenta já em suas primeiras linhas noção que se aproxima das comunidades imaginadas comentada por Hall ao pensar em "ideal espelhado de uma sociedade", ligando-o à formação de uma nação uniforme. A definição prossegue com alguns pontos que aludem ao multiculturalismo e à soma de culturas em harmonia ao tratar do enriquecimento que nutre as culturas diferentes, ignorando divergências e desavenças. Tal conceituação pode se mostrar problemática em sua defesa por parecer exaltar o conceito de estado-nação como sinônimo de cultura e minimizar conflitos, assemelhando-se a definições uniformizantes de séculos passados.

A relação entre cultura e tempo foi lembrada em diversas produções, seja para reafirmar a ideia de tradições seja para mostrar as mudanças que influenciam os povos e suas culturas:

Texto 10: Cultura é tudo que se prolonga no decorrer do tempo. A cultura pode ser encontrada em danças, festas, músicas e
Texto 11: Cultura é a herança de uma sociedade. Podemos dizer que ela é passada de geração em 


\begin{tabular}{|c|c|}
\hline $\begin{array}{c}\text { culinária. A cultura é passada de geração em } \\
\text { geração. }\end{array}$ & $\begin{array}{l}\text { geração, podendo haver algumas mudanças, } \\
\text { porém a essência permanecerá a mesma. }\end{array}$ \\
\hline $\begin{array}{l}\text { Texto 12: Cultura está relacionada aos contextos } \\
\text { históricos, às influências sofridas por cada } \\
\text { comunidade e às expressões que ela partilha, que } \\
\text { podem ser observadas nos gestos, danças, } \\
\text { linguagens, artes, entre outros. }\end{array}$ & $\begin{array}{l}\text { Texto 13: Cultura é um conjunto de ideias, } \\
\text { comportamentos, símbolos e práticas que são } \\
\text { passados de geração em geração, por isso, com o } \\
\text { passar do tempo, ela é influenciada com novas } \\
\text { maneiras de pensar e agir. }\end{array}$ \\
\hline
\end{tabular}

O texto 10 trata o tempo como um fator de consolidação da cultura, retomando a ideia de sedimentação apontada por Kramsch; já o Texto 11 aponta possibilidade de mudanças, mas prega que "a essência permanecerá a mesma", ou seja, a tendência é a manutenção e não a alteração dos elementos culturais. Ambos, portanto, afirmam que a cultura está mais próxima da imutabilidade do que da transformação. Por outro lado, os Textos 12 e 13 valorizam a influência da mudança sobre as culturas e sua capacidade de alterá-las conforme "contextos históricos" e "novas maneiras de pensar e agir"; nesses textos, o destaque é dado, portanto, à variação, que possibilita às culturas a capacidade de se transformarem ao longo do tempo. $\mathrm{O}$ Texto 14, a seguir, apresenta uma reflexão mais aprofundada sobre a relação entre cultura, tempo e sociedade:

Texto 14: Quando usamos a palavra cultura na maioria das vezes não nos damos conta do peso histórico que essa palavra possui, isso porque ela é tão comum aos nossos ouvidos que esquecemos que desde que o mundo existe a cultura já começa a tomar forma e adquirir sentido. A cultura é de extrema importância para a formação do indivíduo perante a sociedade em que ele vive, pois é ela que vai moldar a pessoa para que ela consiga viver entre as demais. Várias atitudes que hoje consideramos naturais nada mais são do que reflexos da nossa cultura e é muito importante que se dê valor para elas.

A percepção de que a cultura é algo que vem se formando ao longo da história da humanidade ("desde que o mundo existe") faz compreender um outro fato importante: "não nos damos conta do peso histórico que essa palavra possui" nem mesmo da sua influência sobre a sociedade. A capacidade que a cultura tem de interferir em nossas vidas é apontada ao destacar que ela é a responsável por nos moldar para a convivência em sociedade. Mais uma vez vemos a ideia de sedimentação da cultura abordada por Kramsch, na frase final do texto: atitudes naturais, comuns para os integrantes de determinada cultura, são reflexos dela própria (e de sua 
história). Essa concepção se entranha de tal maneira na sociedade, e no indivíduo, que passa a fazer parte do que ele é, o que explica as definições apresentadas nos Textos 15 a 17 abaixo:

\begin{tabular}{|c|c|}
\hline $\begin{array}{c}\text { Texto 15: A cultura faz parte do } \\
\text { comportamento humano. }\end{array}$ & $\begin{array}{c}\text { Texto 16: Cultura é basicamente o que define o ser } \\
\text { humano, seja no modo de falar, agir ou se vestir. }\end{array}$ \\
\hline $\begin{array}{c}\text { Texto 17: A cultura é a expressão de um povo. É a partir dela que o homem cria sua identidade e se } \\
\text { manifesta singular ou pluralmente. Porém existe uma padronização do conceito ditando o que é } \\
\text { cultura, onde apenas expressões eruditas podem ser consideradas como tal. }\end{array}$ \\
\hline
\end{tabular}

Abordar a cultura como algo que "faz parte do comportamento humano" ou "que define o ser humano" guarda certa aproximação com o conceito formulado por Geetz de "um conjunto de histórias que contamos a nós mesmos sobre nós mesmos", o que Monte Mór mostrou ser comum ao pensamento contemporâneo, não ligando a cultura exatamente a um conjunto de características gerais capaz de definir todo um aglomerado de pessoas. O Texto 17, apesar de utilizar o termo "expressão de um povo", logo em seguida marca que as manifestações de identidade podem ser singulares ou plurais. Além disso, é bastante significativa a observação sobre a padronização do conceito de cultura relacionando-a apenas ao que é erudito. Tal reflexão, apesar de não ter sido aprofundada, remete à dicotomia apontada por Santos de cultura popular x cultura erudita, despontando uma centelha questionadora sobre a (im)possibilidade de medir o valor de cada cultura. Esse ponto foi abordado em outros textos:

Texto 18: Não existe sociedade sem cultura pois sua formação está sempre presente seja na língua local, na culinária, nos costumes, entre outras características.
Texto 19: A cultura é um dos bens históricos mais valiosos de uma determinada sociedade ou comunidade. Independente de ser pequena ou não, cada cultura é de extrema importância para as pessoas daquele lugar.

O Texto 18 parte de uma afirmação significativa: não existe sociedade sem cultura, ou seja, ela se faz presente sempre em qualquer grupo humano. Apesar de não fazer referência direta, a alegação dá a entender que há pessoas que consideram a existência de sociedades sem cultura, em consonância com o apresentado no Texto 17. Ambos creem que tal afirmação não é plausível. 
O Texto 19 apresenta um problema estrutural que causa certa confusão de ideias: a afirmativa "independente de ser pequena ou não" parece se referir à cultura, porém (conforme explicado pelo aluno) alude ao tamanho da comunidade/sociedade. Após a explanação fica evidente que o aluno pretendia afirmar que não há cultura mais ou menos importante, sendo todas elas extremamente significativas para seus praticantes, o que ecoa nas ideias de Santos sobre os sentidos que cada cultura tem para os que a vivem, não sendo, portanto, possível medir seus valores.

\section{CONSIDERAÇÕES FINAIS}

As definições apresentadas pelos futuros bibliotecários refletem suas histórias de vida, seus aprendizados ao longo do tempo, suas ponderações pessoais, suas culturas enfim, pois, como aponta Fonseca (2016, p. 26), "somos indivíduos carregados de influências, e muitas delas marcadas por parcialidades que nem sempre conhecemos". É, portanto, natural que alguns dos conceitos descritos apresentem generalizações e idealizações decorrentes da cultura em que os estudantes se desenvolveram.

É importante lembrar ainda que tais classificações perpassam as ideias da própria autora deste artigo, já que as palavras dos alunos foram analisadas por sua lente cultural, que também não é isenta, como já afirma Santos (2006). Trata-se, portanto, de uma visão de cultura (dos futuros bibliotecários) a partir de outra visão de cultura (da autora do artigo).

Porém é preciso destacar que o conjunto de respostas no geral parece bastante satisfatório ao não reproduzir preconceitos quanto ao diferente ou juízos de valores excessivamente positivos ou negativos sobre si próprios. O prejulgamento do alheio poderia ser uma tentativa de segmentação das pessoas pertencentes àquelas culturas, mantendo afastado o que é diferente, algo que não é desejável a um profissional que pretende trabalhar com o acesso ao conhecimento do mundo escrito. Já as visões em demasiado positivas ou negativas de sua cultura (e consequentemente de si próprio, já que participante dela) não seriam adequadas por menosprezar o outro, no primeiro caso, ou exaltar o alheio, no segundo, sendo ambas generalizantes e pouco munidas de dados empíricos ou científicos que as embase.

Por fim, tais reflexões não devem ocorrer apenas em momentos como o desenvolvimento de textos em sala de aula por estudantes de Biblioteconomia ou a produção de artigo acadêmicos como este. É necessário um processo de manutenção dessas reflexões, em 
especial por aqueles que exercem (ou exercerão) significativa influência na formação de outros indivíduos, sejam profissionais ligados à educação formal (os professores, por exemplo), sejam de outros âmbitos de desenvolvimento do ser humano (como os bibliotecários). Afinal, como afirma Fonseca (2016, p. 26):

Pensar sobre cultura é um ato contínuo e indispensável para que possamos compreender como caminham as sociedades, a partir do olhar de cada sujeito, no espaço das suas práticas sociais, onde deixa entrever seus valores, convicções, ideias, crenças, preconceitos, e tudo aquilo que constitui a sua visão de mundo.

Pensar sobre a cultura, portanto, é um exercício de reflexão sobre o próprio ser humano, sobre seu passado e, principalmente, sobre seu futuro. Tal prática deve ser comum a todos aqueles que fazem parte da humanidade, já que diz respeito a todos eles. É importante, então, que ela não se restrinja a um seleto grupo de pessoas, mas possa ser discutida por todos, em todos os ambientes e em todos os tempos. Neste ponto, a educação, formal ou não, exerce papel fundamental, podendo ser incluído no que Borelli e Pessoa (2011, p. 28) classificaram como "o conhecimento a serviço da sociedade".

Apesar de as autoras se referirem especificamente à formação de professores, o contexto dá a liberdade para expandir o pensamento a outros profissionais, como os bibliotecários: "como intelectuais críticos, precisamos ter a clara noção dos interesses a que queremos servir. [...] não devemos buscar o saber pelo saber pois nossos esforços devem se voltar para as pessoas do mundo real e para a transformação de suas condições de vida”. Logo, é papel também desses profissionais utilizar seus saberes para modificar a realidade daqueles que buscam conhecimento nos livros, expandindo suas visões de mundo e de cultura, mostrando o diferente não como estranho, mas como semelhante, apesar das diferenças.

\section{NOTAS}

\footnotetext{
${ }^{1}$ Texto original: "For the cultural ways which can be identified at any one time have evolved and become solidified over time, which is why they are so often taken for natural behavior. They are sedimented in the memories of group members who have experienced them firshand or merely heard about them, and who have passed them on in speech and writing from one generation to the next. [...] The culture everyday practices draws on the culture of shared history and traditions."

${ }^{2}$ Texto original: "What comes to our mind when we think of French culture? Souvenirs, Paris, la musique, le cinema, the romantic French language. Are these aspects positive or negative? Now, when we think about the Iraqi culture (or the Arabs, Afghans, the Pakistani), what comes to our minds? War, fight, bombs, death, suicide men, ugly Arabic language. Are these positive or negative aspects of the Arabic world? Obviously not every French person is romantic or "cult" just like not every Iraqi is a terrorista."
} 


\section{REFERÊNCIAS}

BORELLI, J. D. V. P; PESSOA, R. R. Linguística aplicada e formação de professores: convergências da atuação crítica. In: BORELLI, J. D. V. P; PESSOA, R. R. (Org.). Reflexão e crítica na formação do professor de língua estrangeira. Goiânia: Editora UFG, 2011

FERRAZ, D. M.; SILVA, A. C. Língua e Cultura em Babel: problematizando o outro. IN: FERRAZ, D. M; TOMAZ, M. M. Línguas, c(c)ultura(s) e educação linguística. 1. ed. Curitiba: CRV, 2016.

FERRAZ, D. M. Language and culture fostering peace: the contributions of critical education. Revista Humanidades, Tecnologia e Cultura, Bauru-SP, v. 03, n. 01, 2013.

FONSECA, Camila Oliveira. De onde falamos de cultura? IN: FERRAZ, D. M; TOMAZ, M. M. Línguas, c(c)ultura(s) e educação linguística. 1. ed. Curitiba: CRV, 2016.

HALL, S. A identidade cultural na pós-modernidade. 11. ed. Rio de Janeiro: DP\&A, 2006.

KRAMSCH, C. Language and culture. Oxford: Oxford University Press, 2011.

MONTE MÓR, W. Língua e diversidade cultura nas Américas multiculturais. Interfaces Brasil/Canadá, Porto Alegre, v. 1, n.2, 2002.

SANTOS, J. L. O que é cultura? São Paulo: Brasiliense, 2006.

SILVEIRA, F. J. N. Biblioteca, memória e identidade social. Perspectivas em Ciência da Informação, Belo Horizonte, v. 15, n. 3, p. 67-86, set./dez. 2010. Disponível em: < http://www.brapci.inf.br/index.php/article/view/0000009464/

566531e524cb32f703d69ad9afceadc1>. Acesso em: 08 nov. 2018

SOUZA, L. M. M. Cultura, língua e emergência dialógica. Revista Letras \& Letras, Uberlândia-MG, v. 26, n. 2, 2010. 